\title{
Sleep, Sleep Disorders, and Sexual Dysfunction
}

\author{
Jae Wook Cho ${ }^{1,2}$, Jeanne F. Duffy ${ }^{1}$ (iD \\ ${ }^{1}$ Division of Sleep and Circadian Disorders, Departments of Medicine and Neurology, Brigham and Women's Hospital and Division of \\ Sleep Medicine, Harvard Medical School, Boston, MA, USA, ${ }^{2}$ Department of Neurology, Pusan National University Yangsan Hospital, Pusan \\ National University College of Medicine, Yangsan, Korea
}

Good sleep is necessary for good health. Sleep health is increasingly recognized as important for physical and mental health by both the medical profession and the general public, and there is great interest in how to avoid and treat sleep disorders and problems. Recent research indicates that insufficient sleep, disrupted sleep, and sleep disorders affect many aspects of human health including sexual function. In fact, patients with urological disorders or erectile dysfunction (ED) may have a sleep disorder that contributes to their urological or sexual dysfunction. Obstructive sleep apnea, insomnia, shift work disorder, and restless legs syndrome are all common sleep disorders and are associated with ED and/or other urological disorders. Therefore, careful attention should be paid to the diagnosis and treatment of concomitant sleep disorders in patients with sexual dysfunction. In this review, we provide an overview of what sleep is and how it is assessed in the clinic or laboratory; our current understanding of the functions of sleep and sleep health; a description of common sleep disorders, as well as how they are diagnosed and treated; and how sleep and its disorders are associated with male sexual dysfunction. Sleep is considered to be a 'third pillar of health', along with diet and exercise. With an understanding of common sleep disorders and how they can impact male sexual function, the urologist can ensure that sleep disorders are considered as a contributor to sexual dysfunction in their patients in order to provide them with the optimal treatment for overall health.

Keywords: Erectile dysfunction; Sexual dysfunctions, psychological; Sleep; Sleep wake disorders; Testosterone

This is an Open Access article distributed under the terms of the Creative Commons Attribution Non-Commercial License (http://creativecommons.org/licenses/by-nc/4.0) which permits unrestricted non-commercial use, distribution, and reproduction in any medium, provided the original work is properly cited.

\section{INTRODUCTION}

As men age into midlife and beyond, they frequently experience changes in their sexual health, and those changes can lead to dysfunction. Most of the changes are due to diminished sex hormone levels, such as testosterone. Decreased testosterone can lead to erectile dysfunction (ED), decreased libido, loss of pubic and body hair, impaired orgasmic and ejaculatory function, etc. [1]. ED, due to the inability to achieve and maintain a sufficient penile erection in order to have satisfactory sexual intercourse [2], is the most recognized and distressing of these disorders, and often leads patients to seek treatment. ED is quite prevalent, especially among the middle-aged and older population, affecting more than half $(52 \%)$ of men aged 40 to 70 years [3]. ED is typically assumed to be due to the natural aging process, but it may also occur secondary to other disorders, due to medical treatment, or to result from altered emotional states including fear, depression, or

Received: May 30, 2018 Revised: Jun 12, 2018 Accepted: Jun 18, 2018 Published online Aug 14, 2018

Correspondence to: Jeanne F. Duffy iD https://orcid.org/0000-0003-4177-4179

Division of Sleep and Circadian Disorders, Departments of Medicine and Neurology, Brigham and Women's Hospital, 221 Longwood Avenue, BLI438, Boston, MA 02115, USA.

Tel: +1-617-732-7995, Fax: +1-617-732-4015, E-mail: jduffy@hms.harvard.edu 
low self-esteem [4]. Regardless of origin, ED frequently has a strong negative effect on quality of life.

Good sleep is necessary for good health and wellbeing [5]. Recently, sleep medicine and sleep disorders have received more attention among physicians and the general public. Some of this attention is due to recent research that indicates clearly that insufficient sleep and sleep disorders affect many aspects of human health, and when untreated can cause serious illness. In the past, sleep disorders were not considered as risk factors for ED. However, sleep has been found to be disrupted in ED populations and the association between sleep disruption, sleep disorders, and ED has been increasingly studied.

In this review, we begin with a brief overview of what sleep is and how it is assessed in the clinic or laboratory, our current understanding of the functions of sleep, common sleep disorders, and how sleep and its disorders are associated with sexual dysfunction.

\section{MAIN BODY}

\section{Sleep}

Sleep is an essential biological process that is now appreciated as vital to both physical and mental health. Sleep is exhibited by all mammals, and sleeplike behavior is seen in birds, reptiles, amphibians, and even insects. Despite the fact that adults spend approximately one third of their life sleeping, for a long time sleep was ignored by physicians and scientists alike. Beginning in the 1980's, sleep disorders began to be systematically studied, understood, and more widely diagnosed, and sleep medicine became a medical specialty. More recently, as the quest for understanding the functions of sleep have been pursued by sleep scientists, we have begun to understand how important sufficient sleep quality and duration are to physical and mental health and quality of life.

Sleep consists of two different states, rapid eye movement (REM) sleep and non-REM sleep. For clinical purposes, sleep is divided into stages based on the polysomnogram (PSG), with each stage being characterized by particular electroencephalographic (EEG) waveforms as well as muscle tone (via electromyogram, EMG) and eye movements (via electrooculogram, EOG). NonREM sleep is divided into three stages (called N1-N3), with N1 the 'lightest' and N3 the 'deepest' (Fig. 1A, 1B). $\mathrm{N} 1$ represents a transitional state between wake and sleep, N2 is the most abundant stage of sleep and is characterized by EEG waveforms called sleep spindles and K-complexes, and N3 is the deepest stage of sleep and is characterized by delta waves (also called slow waves, hence N3 is sometimes referred to as slow wave sleep). As the individual goes from N1 to N3, the EEG frequency slows and the amplitude becomes higher, respiratory rate and heart rate slow, and muscle tone relaxes. REM sleep is characterized by a fast frequency EEG, absent muscle tone, and REMs (Fig. 1C). In a typical night, non-REM and REM will alternate back and forth four to five times, with N3 sleep in the first 1-2 cycles and REM sleep duration becoming longer as the night progresses.

Human sleep and wakefulness is co-regulated by two
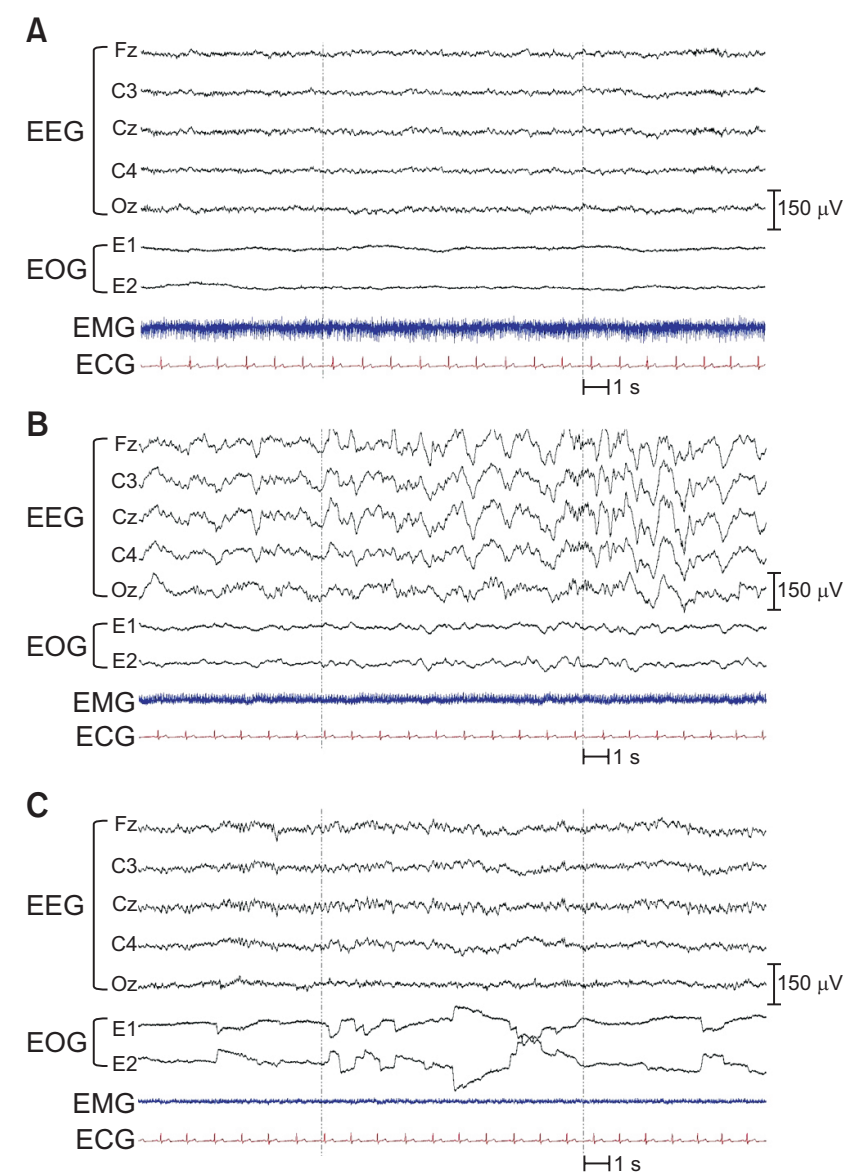

Fig. 1. Polysomnograms showing different sleep stages. (A) N1 nonrapid eye movement (REM) sleep is characterized by low amplitude mixed frequency electroencephalography (EEG) representing light sleep. (B) In contrast, high amplitude slow frequency EEG characterizes N3 non-REM sleep, the 'deepest' stage of sleep. Note that electromyography (EMG) tone is reduced compared with N1 sleep. (C) REM sleep is characterized by unique REMs on electrooculography (EOG) and low or absent EMG, with EEG showing low amplitude mixed frequency. ECG: electrocardiography. 
interacting physiological processes, the circadian timing system (Process C) and a sleep-wake homeostatic process (Process S), first modeled by Borbély [6] more than 35 years ago as the 'two process model for sleep regulation'. The sleep-wake homeostatic process refers to a process by which the longer one is awake, the more sleep pressure they accumulate, and when they go to sleep that sleep pressure begins to dissipate. In the two-process model, the buildup of Process $\mathrm{S}$ is an exponential saturating function, while the dissipation is an exponential decaying function. If sleep is long enough and wake is not extended, dissipation of all sleep pressure is accomplished within the sleep episode, beginning each wake episode at the same (low) level. Process $\mathrm{C}$ in the original two-process model referred to a rhythmic drive for sleep from the circadian timing system. In this way, adult human sleep can be long and consolidated, and wake can be long and stable each day. Dijk and Czeisler [7] showed that the circadian rhythm of sleep-wake propensity is timed so that the strongest drive for wake occurs in the late evening, just before the usual sleep time, while the strongest drive for sleep occurs in the early morning, just before usual wake time. Thus, when sleep pressure has built up to a high level near the end of the wake episode, the circadian drive for wake is high, to oppose it and maintain wake, while near the end of the night when most of the sleep pressure has dissipated the circadian drive for sleep is high, allowing for an extended and consolidated sleep episode.

\section{Sleep-related erection}

Sleep-related erection (SRE) is a natural and involuntary phenomenon occurring typically during REM sleep in healthy males. SRE was called 'nocturnal penile tumescence' in work by Karacan [8], but current recommendation by the International Classification of Sleep Disorders is to use the term SRE [9].

There is no clear theory about why and how SREs occur, but results from a study in rats in which lesions of the lateral preoptic area of the brain were made suggested that SREs are regulated by the hypothalamus [10]. It is known that SREs appear from infants to old age, and the magnitude and duration tends to decline with aging. SREs are considered to have a different mechanism from the erections that occur by sensory stimuli or fantasy [11]. Karacan [8] suggested that SRE testing is useful to differentiate psychogenic from organic ED, but other urologists demonstrated psychological factors can affect SREs, such as depression, anxiety, and fatigue [12,13]. Currently, it is believed that the overall quality of sleep is more important for SREs than whether they are caused by psychogenic or organic factors.

While at one point SRE testing was carried out in sleep laboratories along with polysomnography, this is no longer the case. There are no definite indications for SRE testing in the sleep laboratory due to the expense of overnight polysomnography, and because it is no longer considered useful in the diagnosis of ED or in attempting to determine whether the ED has an organic or psychogenic cause. Oral agents for ED are now available regardless of the origin of ED. Therefore, SRE testing could be considered only in very special situations, such as in individuals who are non-responders to medical therapy, those with abnormal SRE documented with a home screening device, or for legal cases requiring objective erectile evaluation [10].

\section{Sleep disorders}

\section{1) Obstructive sleep apnea}

Obstructive sleep apnea (OSA) is a common sleep disorder characterized by loud snoring and reduced or absent airflow due to partial or complete collapse of the upper airway. An apneic event is defined as a decrease of airflow of more than $90 \%$ for at least 10 seconds while respiratory effort continues (Fig. 2). A hypopnea is defined by a $30 \%$ to $90 \%$ decreased airflow accompanied by a $3 \%$ or greater oxygen desaturation [9]. As the partial or complete obstruction continues, oxygen saturation falls, and this ultimately triggers a brief arousal during which the patient gasps to reopen the airway. The arousals typically do not awaken the patient, who often is unaware of the occurrence of these events the next morning. The severity of OSA is measured by the number of events per hour of sleep (the apneahypopnea index, AHI), with stratification into normal $(\mathrm{AHI} \leq 5)$, mild $(5<\mathrm{AHI}<15)$, moderate $(15 \leq \mathrm{AHI}<30)$, and severe $(\mathrm{AHI} \geq 30)$.

OSA causes sleep fragmentation (from the frequent arousals), hypoxemia, loud snoring, breathing interruptions, awakenings due to choking, and often (but not always) is accompanied by daytime sleepiness [14]. Epidemiologic studies have found that the prevalence of OSA is $4.0 \%$ to $32.8 \%$ in middle-aged men $[15,16]$. Data 


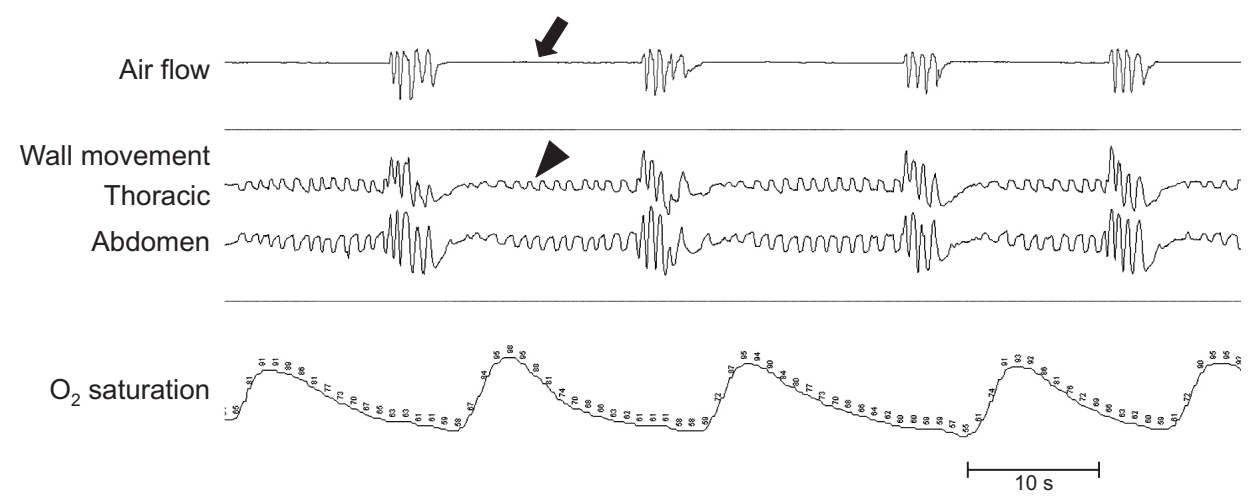

Fig. 2. Obstructive sleep apnea events on polysomnogram. A full diagnostic polysomnogram includes electroencephalography, electrooculography, and electromyography, along with a series of sensors to measure nasal airflow, thoracic and abdominal wall movement, and oxygen saturation. Complete cessations of airflow (arrow) with continued thoracic and abdominal wall movements representing respiratory efforts (arrowhead) are accompanied by falling oxygen saturation. This drop in oxygen saturation triggers a brief arousal during which the patient gasps and airflow is briefly re-established, but once he falls back asleep the obstruction reoccurs.

from a recent Korean questionnaire study found an OSA prevalence of $22.4 \%$ among people over 60 years of age [17]. While a large neck size, being overweight or obese, or having particular craniofacial features can lead to OSA, even those of normal weight and craniofacial structure can develop OSA, particularly as they get older. Even though the prevalence of OSA is high, it is estimated that at least $80 \%$ of moderate to severe OSA cases are still undiagnosed [18]. OSA is typically diagnosed with an all-night PSG that includes EEG, EOG, and EMG for sleep staging, electrocardiogram, a nasal pressure transducer to measure airflow, an oximeter, as well as thoracic and abdominal bands to measure respiratory effort. Left untreated, OSA can lead to serious medical conditions including hypertension, atrial fibrillation, congestive heart failure, myocardial infarction, stroke, chronic obstructive pulmonary disease, type 2 diabetes, and depression [19].

Several studies have shown a high incidence of ED among male OSA patients, ranging from $47.1 \%$ to $80.0 \%$ [20-24]. The severity of OSA is considered to be an important factor in the development of ED [25,26], however, this finding is not consistent [27]. A Korean study by Shin et al [28] showed that ED is associated with decreased minimum oxygen saturation, not with AHI. The underlying mechanism of interaction between OSA and ED remains unknown, although several theories have been proposed, including a hormonal effect of testosterone, peripheral neuropathy due to hypoxemia, or vascular endothelial dysfunction.

Many studies have found that male patients with OSA have lower serum testosterone, and there is a negative correlation between AHI, oxygen desaturation index, and testosterone level $[21,25,29]$. On the other hand, testosterone is believed to play a role in the pathogenesis of sleep apnea, and testosterone supplementation might worsen OSA. Schneider et al [30] demonstrated that treating hypogonadal patients with androgen significantly increased the number of apneas and hypopneas. Similarly, Cistulli et al [31] reported a 13-year-old boy with Marfan's syndrome showed a worsened OSA after testosterone injection. Therefore, the relationship between testosterone and OSA is complicated, and caution should be taken when considering treating a patient who has OSA with testosterone.

An altered bulbocavernous reflex among OSA patients, a widely accepted method to assess pudental neuropathies, is supportive evidence of the relationship between ED and peripheral nerve dysfunction [32]. In addition, the elevation of inflammatory markers such as high-sensitivity C-reactive protein, tumor necrosis factor $\alpha$, interleukin (IL)-6, and IL-8 in patients with severe OSA with ED suggests that vascular endothelial dysfunction is involved in the pathogenesis of $\mathrm{ED}$ in OSA [33].

Continuous positive airway pressure (CPAP) is the first-line therapy for OSA. A number of studies have been performed to measure therapeutic effects of CPAP on ED in OSA patients. However, the results of those studies on the efficacy of CPAP in treating ED are inconsistent. Budweiser et al [34] reported beneficial long-term effects of CPAP on erectile and sexual function. Just one month of CPAP therapy elevated International Index of Erectile Function (IIEF-5) score 
as well as serum levels of follicle stimulating hormone, luteinizing hormone, and testosterone, indicating improvement of sexual function [21]. Zhang et al [25] reported that 3 months of CPAP improved IIEF-5 scores of OSA patients significantly, despite no difference in their testosterone levels. Interestingly, in a study by Acar et al [35] which estimated sexual function by questionnaires, CPAP therapy improved not only the patients' IIEF scores, but also their female partner's sexual quality of life assessed by Female Sexual Function Index and Beck Depression Inventory. On the other hand, no meaningful changes of testosterone level or sexual function were observed in other studies following CPAP treatment, although daytime sleepiness and AHI were decreased effectively [36,37].

Another treatment modality for OSA, uvulopalatopharyngoplasty (UPPP), has shown promising results for ED [38], with better efficacy than CPAP or a mandible advancement device [39]. However, additional evidence from studies of surgical treatments are still required before UPPP is recommended for OSA with ED.

In addition to conventional OSA treatments for OSA patients with ED, direct management of ED may be helpful. Sildenafil has been demonstrated to produce better results in patients with OSA and ED than CPAP, leading to higher numbers of successful attempts and higher IIEF scores [40]. As noted above, testosterone supplementation might be considered as a therapeutic option given the association between OSA and low testosterone levels. However, a randomized placebo-control study of 67 obese men with OSA found that intramuscular injection of 1,000 mg testosterone increased sexual desire but had no effect on ED, frequency of sexual attempts, orgasmic ability, or quality of life [41].

Even though many studies demonstrate that OSA is associated with ED, the mechanisms underlying that relationship and the efficacy of treatments remain to be elucidated. This comorbidity may impair quality of life, not only for the patient but also for their partner. Due to this association and the under-diagnosis of OSA, a simple questionnaire at the andrology clinic would be helpful as a screening tool for detecting OSA and referring patients at high risk of OSA to a sleep specialist [42].

\section{2) Insomnia, chronic sleep insufficiency}

Insomnia is one of the most highly prevalent sleep disorders. While difficulty initiating sleep is a common insomnia symptom, other sleep problems that are considered symptoms of insomnia include difficulty maintaining sleep, awakening earlier than desired, resistance to going to bed on an appropriate schedule, and difficulty sleeping without parents (Table 1) [9]. According to previous epidemiologic studies, approximately $30 \%$ to $35 \%$ of the population has at least one of the insomnia symptoms occasionally, and $9 \%$ to $10 \%$ of the population meet the diagnostic criteria for insomnia disorder $[43,44]$. A Korean survey study also showed similar results, finding that $22.8 \%$ of the 5,000 people complained of insomnia, especially older people [45].

Sexual dysfunction is more common among older men, and insomnia has been found to be an independent risk factor related to sexual dysfunction, along with cardiovascular disease, diabetes, and depression [46]. The most likely explanation for the mechanism underlying the association between insomnia and sexual dysfunction is a decrease in the level of testosterone. Testosterone has a diurnal rhythm of production, starting to rise at sleep onset and reaching a peak during the first REM sleep bout [47]. Therefore, circulating testosterone levels are higher during sleep than during waking, and insomnia or insufficient sleep could adversely affect the level of testosterone via shortening sleep duration or altering the structure of sleep. In fact, it has been demonstrated that sleep loss during the second half of the night significantly reduces morning testosterone levels [48].

Chronic sleep restriction refers to an ongoing sleep duration shorter than normal, typically due to lifestyle choices made by the individual. In modern industrialized society with round-the-clock activities, the average sleep duration tends to shorten [49], and survey studies in the US and South Korea have found that $43.8 \%$ and $32.4 \%$ of the population reports sleeping less than 6 hours per night, respectively [50,51]. Chronic sleep restriction is associated with numerous medical problems, including type 2 diabetes, metabolic syndrome, obesity, depression, hypertension, and heart disease [52-58].

In addition to those health consequences of chronic insufficient sleep, numerous animal and human studies have demonstrated that insufficient sleep is related to a decreased of testosterone levels [59-61]. Leproult 
Table 1. Diagnostic criteria for chronic insomnia disorder (from the International Classification of Sleep Disorders-3)

\begin{tabular}{ll}
\hline Criteria A-F must be met $^{\text {a }}$ & \\
\hline A. Sleep disturbance/complaint & 1. Difficulty initiating sleep \\
(one or more) & 2. Difficulty maintaining sleep \\
& 3. Waking up earlier than desired \\
& 4. Resistance to going to bed on appropriate schedule \\
& 5. Difficulty sleeping without parent or caregiver intervention \\
& 1. Fatigue/malaise \\
B. Associated consequence (one or more & 2. Attention, concentration, or memory impairment \\
of the following related to the nighttime & 3. Impaired social, family, occupational, or academic performance \\
sleep difficulty) & 4. Mood disturbance, irritability \\
& 5. Daytime sleepiness \\
& 6. Behavioral problems (e.g., hyperactivity, impulsivity, aggression) \\
& 7. Reduced motivation, energy, initiative \\
& 8. Proneness for errors, accidents \\
& 9. Concerns about or dissatisfaction with sleep \\
& Sleep difficulty and associated consequence occurs at least 3 nights per week. \\
& Sleep difficulty and associated consequence is present for at least 3 months. \\
C. Frequency & Sleep difficulty occurs despite adequate opportunity and circumstances for sleep. \\
D. Duration & Sleep-wake problems are not better explained by another sleep disorder, a coexisting mental \\
E. Adequate opportunity & disorder, or coexisting medical condition and are not attributed to the physiologic effects of a \\
F. Relationship to another condition & substance.
\end{tabular}

a'Data from American Academy of Sleep Medicine (AASM, 2014) [9].

and Van Cauter [62] demonstrated this in a highly controlled laboratory study. They studied a group of 10 healthy young men whose sleep was restricted to 5 hours per night for 8 nights and found that serum testosterone levels decreased markedly. Another study of 33 hours of acute sleep loss in 24 healthy young men found lowered salivary testosterone levels and reactive aggression but no change in cortisol concentrations [63]. In contrast to these studies showing significant results, another study with sleep restriction to 4 hours per night (4 am-8 am) for five nights found only a small trend towards decreasing testosterone [64]. The authors of the latter study attributed the inconsistency of their finding to methodological differences related to the duration and timing of sleep.

Testosterone plays an important role in sexual function, muscle mass, bone mineral density, and even mood. Chronic insomnia or chronic sleep restriction could therefore not only cause decreases in testosterone levels, but could also have marked implications for health and quality of life, including sexual function [65-67].

\section{3) Circadian rhythm sleep disorders}

Circadian rhythm sleep disorders are problems with sleep characterized by an inability to sleep at the de- sired time, rather than a dysfunction with the underlying mechanisms generating sleep [68-72]. These sleeptiming disorders result in a mismatch between the clock hour at which sleep is attempted and the underlying biological time at which sleep is promoted by the circadian timing system. Circadian rhythm sleep disorders can be due to transient, self-correcting factors, such as what happens when traveling rapidly to a new time zone ('Time Zone Change Syndrome', 'Jet Lag') or when attempting to stay up at night for work and sleep during the daytime hours ('Shift Work Disorder'). While jet lag is self-correcting, it affects millions of travelers annually and can have a high cost in terms of productivity. For shift workers, the impacts continue for as long as the work schedule includes overnight work or early shift start times.

Shift work is prevalent all over the world, comprising more than $15 \%$ of the workforce [73]. The proportion of shift workers in some professions can reach as high as $50 \%$, including police, firefighters, manufacturing employees, transportation, and hospital workers. Many industries that formerly had few or no shift workers now do so given our 24/7 culture, including retail, customer support, and food-service [74]. Working at night or on a rotating schedule results in frequent shifting of the timing of sleep-wakefulness, feeding-fasting, and 
rest-activity with respect to the solar day and with respect to the underlying biological clock timing. This poses a serious threat to the shift worker's physical, mental, and psychosocial health [73,75-77]. In fact, the disruption caused by shift work is recognized as a circadian rhythm sleep disorder in both the International Classification of Sleep Disorders and the Diagnostic and Statistical Manual of Mental Disorders-fourth edition. Even those workers who choose to work at night because of higher pay or to accommodate childcare or other demands report that working at night can negatively influence their health and safety [78,79]. Adverse consequences of shift work include gastrointestinal disorders [70,80-82], increased risk of accidents while at work and while commuting home [70,79,83-85], greater likelihood of depression, increased risk of myocardial infarction and cardiovascular disease [86-88], greater risk for developing certain cancers, metabolic syndrome [89-91], and more sleep complaints [72,73,75,92-96]. While female workers who experience frequent transmeridian travel or night work are reported to experience higher rates of menstrual irregularities, miscarriages, and difficulty becoming pregnant compared with day workers [97-99], sexual dysfunction in male shift workers has received much less attention.

Given the research results showing that testosterone secretion starts to rise at sleep onset and reach the highest point at the first REM sleep cycle, it can be inferred that sleep disruption by shift work should influence testosterone secretion. A small study with 4 healthy shift workers demonstrated a significant increase of melatonin and decrease of testosterone compared to a control group [100]. Another experimental study in the lab showed that fragmented sleep resulted in a decrease of REM sleep and a corresponding loss of the testosterone surge [47]. Recently, Pastuszak et al [101] found that nonstandard shift workers with poor sleep quality had a greater risk for sexual dysfunction and hypogonadal symptoms. Interestingly, there was no association between sleep quality and levels of sexual hormone including testosterone, estrogen, folliclestimulating hormone, and luteinizing hormone in that study. That result suggested that the poor sleep quality of nonstandard shift workers may have a negative impact on hypogonadal symptoms regardless of testosterone levels.

Three other circadian rhythm sleep disorders can result from an intrinsic origin, causing a chronic mis- match between the time when sleep is attempted and the patient's ability to sleep. Advanced and Delayed Sleep Phase Disorders result when sleep regularly occurs at times that are earlier or later than desired. Advanced sleep phase disorder (ASPD) occurs when sleep is earlier than desired, and occurs most often in the elderly [68]. Delayed sleep phase disorder (DSPD) is characterized by late sleep-wake times, and sleep onset insomnia and/or an inability to arise at the desired time [68,69], often resulting in negative occupational, educational, and social consequences as a result of the inability to wake at a socially-acceptable time in the morning. Patients with DSPD, when allowed to sleep at their desired times, are able to fall asleep and have normal sleep structure, but when attempting to sleep and wake at earlier (conventional) hours will have abnormally long sleep latencies. Due to the negative consequences associated with the absenteeism and tardiness of DSPD (resulting from the lack of ability to wake up on time), more complaints of DSPD than ASPD are seen clinically [68]. DSPD has been hypothesized to be due in some patients to a circadian period that is significantly longer than 24 hours, and to represent an extreme beyond the normal spectrum of morningness-eveningness. Unlike ASPD and DSPD, non24-hour sleep-wake disorder is characterized by sleep times that progressively delay to a later hour from one day to the next [68]. Non-24-hour sleep-wake disorder occurs in about half of all totally blind individuals $[102,103]$ due to a lack of photic input to the circadian system. In sighted patients, non-24-hour sleep-wake disorder has been hypothesized to develop in some DSPD patients $[104,105]$ as the patient's sleep times move later and later, such that they eventually lose their ability to remain entrained to the 24-hour day, and can result in them becoming unable to function at regular jobs or in school [68]. No studies to date have examined the relationship between these circadian rhythm sleep disorders and sexual dysfunction. Only one study of young healthy university students reported that high testosterone levels are associated with a stronger eveningorientation [106].

\section{4) Restless legs syndrome}

Restless legs syndrome (RLS) is a movement disorder characterized by peculiar sensory symptoms of the legs, including unpleasant discomfort and an irresistible urge to move the legs to relieve the sensations. These 
symptoms are typically worse at rest when lying or sitting, and appear at night or in the evening [107]. The pathophysiology remains elusive, but dysfunction of the dopamine and iron systems in the brain are considered to play a key role [108]. The prevalence of RLS is lower in men, affecting approximately $4.1 \%$ to $7.6 \%$ of men $[109,110]$. Interestingly, the prevalence in men was directly proportional to increasing age in one study [110], whereas another study showed an inverse trend [111]. RLS is frequently found in anemia, pregnancy, iron deficiency, and uremia, especially in hemodialysis patients $[19,108]$.

Although there are only a few studies about RLS and ED, it is thought that RLS is associated with ED [109]. The mechanism of interaction has not been clarified yet, but it may be because RLS and ED have similar biological processes, including autonomic dysfunction and dopamine deficiency. A 6-year prospective study found that RLS was a risk factor for developing ED with a relative risk of 1.33 , and the frequency of RLS symptoms had a linear relationship with the magnitude of the that risk [112]. In a recent case-control study with 50 subjects each, Kurt [113] reported that not only ED but also premature ejaculation is more common in men with RLS than in controls. Among hemodialysis patients, the presence of RLS symptoms was related with sexual dysfunction [114], and in a study of Swedish RLS patients, those with RLS had significantly reduced libido more often than controls [115]. These findings are in agreement with previous studies.

Generally, dopaminergic agents such as pramipexole and ropinorole are used for the treatment of RLS [116]. Gabapentin and pregabalin are also available. There has been no study about the efficacy of treatment of RLS on ED or sexual dysfunction yet. However, an interesting case study of a patient with RLS and ED was reported [117]. The 65-year-old RLS patient was treated with tadafinil, a long-acting phosphodiesterase type 5 inhibitor, for his ED. After the first intake of tadafinil, his RLS symptoms completely disappeared and his ED recovered as well. More studies testing treatments for patients with comorbid ED and RLS are needed.

\section{5) Periodic limb movements during sleep}

Periodic limb movements during sleep (PLMS) is a type of movement disorder consisting of repetitive limb movements most often impacting the lower limbs, especially as extension of the toes, flexion of the ankles and knees and sometimes even the hips, during sleep (Fig. 3). These movements consist of bursts of muscle activity throughout sleep, and can cause both EEG arousals as well as autonomic arousals. Usually, RLS patients tend to have PLMS once they fall asleep [118]. PLMS is a relatively common sleep disorder with a prevalence ranging between $3 \%$ to $26 \%$ of the general population. The prevalence of PLMS has been known to be higher among ED patients, affecting $54 \%$ to $60 \%$, especially men aged greater than 70 years [119,120].

Some RLS studies have shown that dopaminergic treatment also reduced the PLMS indices of RLS/ PLMS patients. Clonazepam showed significant improvement of subjective sleep quality but not PLMS index. Anticonvulsants and gamma-aminobutyric acid agonists are used to treat the symptoms of PLMS as well. However, treatment is often only considered if the patient has frequent arousals or persistent excessive daytime sleepiness [108]. There is insufficient evidence for pharmacologic treatments for PLMS in patients without RLS [116].

\section{6) Narcolepsy}

Narcolepsy is a rare chronic sleep disorder with a prevalence of $0.02 \%$ to $0.06 \%$, affecting both sexes equally [121]. The main symptom is excessive daytime sleepiness or unexpected sleep attacks. Some narcolepsy patients may have cataplexy (a sudden loss of muscle tone provoked by emotion), sleep paralysis, or sleep hallucinations at sleep onset or upon awakening. Narcolepsy is caused by loss of hypocretin (also known as orexin), a neuropeptide involved in regulating vigilance [122].

To date, just a few studies about narcolepsy and

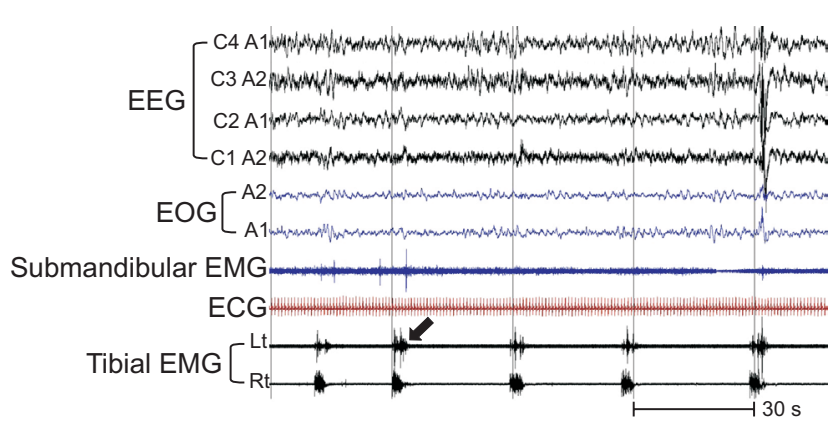

Fig. 3. Polysomnogram from a patient with periodic limb movements during sleep. The bursts of tibial EMG (electromyogram, arrow) occur periodically in both legs. EEG: electroencephalogram, EOG: electrooculogram, ECG: electrocardiogram, Lt: left, Rt: right. 
sexual dysfunction have been carried out. In his study measuring SRE of 28 narcolepsy patients, Karacan [123] found that all the medicated patients had a shorter duration of SREs by $20 \%$, and none of them had full SREs. This finding suggested a connection between $\mathrm{ED}$ and the medications such as stimulants and antidepressants used to treat narcolepsy. In addition, although just two of five untreated patients demonstrated impaired SREs, all five patients complained of their potency, indicating subjective belief seemed to underestimate their erectile function.

\section{7) Nocturia}

The definition of nocturia is the need to wake up one or more times to void urine during sleep [124]. Nocturia is a common complaint in middle-aged and older patients. While young adults rarely report symptoms of nocturia, urological surveys find that approximately half of adults age 60 or older report nocturia, and the prevalence increases with advancing age [125-127]. Sleep surveys also find a high prevalence of nocturia among middle-aged and older individuals, and it is a major cause of sleep disruption. In fact, a majority of older adults with sleep disruption cite the need to void as the cause of their awakening. Therefore, frequent nocturia could produce fragmented sleep and consequentially decrease the level of testosterone [128]. In spite of a lack of evidence, recent studies suggested that low testosterone might be related with nocturia [129,130]. A study of type 2 diabetes patients also found nocturia was associated with ED, and patients with lower levels of testosterone had a higher prevalence of nocturia [131]. It is currently considered that nocturia and testosterone have a negative feedback relationship, in which nocturia produces a decrease of testosterone, and a testosterone decline contributes to the development of nocturia in hypogonadal men with nocturia [46]. Hence, nocturia treatment could increase testosterone levels [132], and testosterone replacement therapy could decrease the frequency of nocturia in reverse [133].

While nocturia is typically thought to be a urological disorder resulting from either an excess production of urine at night or a diminished nocturnal bladder capacity, there is evidence that sleep may play a more causal role in some cases of nocturia. First, there is extensive evidence that sleep apnea can lead to nocturia [134-138] and some studies find that the association between sleep apnea and nocturia is stronger in younger adults [139] and in women [140]. The mechanism by which sleep apnea leads to nocturia is via an increase in the circulating levels of the hormone atrial naturietic peptide ([136]), which in turn leads to suppression of arginine vasopressin. However, even healthy older adults without clinical sleep disorders have lighter and more fragmented sleep than younger adults [141-143], which could lead them to be awakened more easily by internal (bladder stretch signal) or external (noise) stimuli [144]. Once awake, they may then decide to void. In fact, sleep disruption has been suggested as a cause of decreased nocturnal bladder capacity and nocturia [145-147].

Thus, any middle-aged or older patient with nocturia not attributable to a urological cause should be referred for evaluation to a sleep specialist to rule out sleep apnea as the underlying cause [138]. In fact, some have advocated for differential treatments for nocturia subtypes depending on the underlying cause of their disorder [148], and CPAP treatment of sleep apnea has been shown to significantly reduce nighttime voids and other associated symptoms of nocturia [149,150].

\section{CONCLUSIONS}

The relationship between sexual dysfunction and sleep disorders is a highly relevant topic for research and for the clinician. While additional research is needed to elucidate the mechanisms by which sleep disorders cause sexual dysfunction, there is evidence that ED can be a consequence of several sleep disorders. We suggest that andrologists, urologists, and other physicians at clinic consider sleep disorders when they see patients with sexual dysfunction, especially given the fact that many sleep disorders are underdiagnosed. There are brief questionnaires that can help determine whether the patient is likely to have one of the common sleep disorders, and these can help in the diagnosis. If the patient is presumed to have a sleep disorder, referral to sleep medicine specialists should be considered to improve modifiable risk factors of ED.

\section{ACKNOWLEDGEMENTS}

The authors wish to thank Ms. Divya Mohan for assistance with the references and Mr. Brandon J. Lockyer, R.PSG.T. for assistance with the figures.

This work was supported in part by grants from 
the US National Institutes of Health (grant no. R01 AG044416 and P01AG09975).

\section{Disclosure}

The authors have no potential conflicts of interest to disclose.

\section{Author Contribution}

Cho JW and Duffy JF each contributed to the conceptualization of the paper, as well as the original draft preparation, review, and editing. Both reviewed and approved the final version of the paper.

\section{REFERENCES}

1. Jannini EA, Nappi RE. Couplepause: a new paradigm in treating sexual dysfunction during menopause and andropause. Sex Med Rev 2018;6:384-95.

2. Lue TF. Erectile dysfunction. N Engl J Med 2000;342:180213.

3. Feldman HA, Goldstein I, Hatzichristou DG, Krane RJ, McKinlay JB. Impotence and its medical and psychosocial correlates: results of the Massachusetts Male Aging Study. J Urol 1994;151:54-61.

4. NIH Consensus Conference. Impotence. NIH Consensus Development Panel on Impotence. JAMA 1993;270:83-90.

5. Buysse DJ. Sleep health: can we define it? Does it matter? Sleep 2014;37:9-17.

6. Borbély AA. A two process model of sleep regulation. Hum Neurobiol 1982;1:195-204.

7. Dijk DJ, Czeisler CA. Paradoxical timing of the circadian rhythm of sleep propensity serves to consolidate sleep and wakefulness in humans. Neurosci Lett 1994;166:63-8.

8. Karacan I. Nocturnal penile tumescence as a biologic marker in assessing erectile dysfunction. Psychosomatics 1982;23:349-60.

9. American Academy of Sleep Medicine (AASM). International classification of sleep disorders. 3rd ed. Darien (IL): AASM; 2014.

10. Schmidt MH, Schmidt HS. Sleep-related erections: neural mechanisms and clinical significance. Curr Neurol Neurosci Rep 2004;4:170-8.

11. Ware JC, Hirshkowitz M, Thornby J, Salis P, Karacan I. Sleep-related erections: absence of change following presleep sexual arousal. J Psychosom Res 1997;42:547-53.

12. van Driel MF. Sleep-related erections throughout the ages. J Sex Med 2014;11:1867-75.
13. Thase ME, Reynolds CF 3rd, Glanz LM, Jennings JR, Sewitch DE, Kupfer DJ, et al. Nocturnal penile tumescence in depressed men. Am J Psychiatry 1987;144:89-92.

14. Epstein LJ, Kristo D, Strollo PJ Jr, Friedman N, Malhotra A, Patil SP, et al. Clinical guideline for the evaluation, management and long-term care of obstructive sleep apnea in adults. J Clin Sleep Med 2009;5:263-76.

15. Young T, Palta M, Dempsey J, Skatrud J, Weber S, Badr S. The occurrence of sleep-disordered breathing among middle-aged adults. N Engl J Med 1993;328:1230-5.

16. Tufik S, Santos-Silva R, Taddei JA, Bittencourt LR. Obstructive sleep apnea syndrome in the Sao Paulo Epidemiologic Sleep Study. Sleep Med 2010;11:441-6.

17. Sunwoo JS, Hwangbo Y, Kim WJ, Chu MK, Yun CH, Yang KI. Prevalence, sleep characteristics, and comorbidities in a population at high risk for obstructive sleep apnea: a nationwide questionnaire study in South Korea. PLoS One 2018;13:e0193549.

18. Young T, Evans L, Finn L, Palta M. Estimation of the clinically diagnosed proportion of sleep apnea syndrome in middleaged men and women. Sleep 1997;20:705-6.

19. Kryger MH, Roth T, Dement WC. Principles and practice of sleep medicine. 6th ed. Philadelphia (PA): Elsevier; 2017.

20. Guilleminault C, Eldridge FL, Tilkian A, Simmons FB, Dement WC. Sleep apnea syndrome due to upper airway obstruction: a review of 25 cases. Arch Intern Med 1977;137:296-300.

21. Li Z, Tang T, Wu W, Gu L, Du J, Zhao T, et al. Efficacy of nasal continuous positive airway pressure on patients with OSA with erectile dysfunction and low sex hormone levels. Respir Med 2016;119:130-4.

22. Budweiser S, Enderlein S, Jörres RA, Hitzl AP, Wieland WF, Pfeifer M, et al. Sleep apnea is an independent correlate of erectile and sexual dysfunction. J Sex Med 2009;6:3147-57.

23. Teloken PE, Smith EB, Lodowsky C, Freedom T, Mulhall JP. Defining association between sleep apnea syndrome and erectile dysfunction. Urology 2006;67:1033-7.

24. Andersen ML, Santos-Silva R, Bittencourt LR, Tufik S. Prevalence of erectile dysfunction complaints associated with sleep disturbances in Sao Paulo, Brazil: a population-based survey. Sleep Med 2010;11:1019-24.

25. Zhang XB, Lin QC, Zeng HQ, Jiang XT, Chen B, Chen X. Erectile dysfunction and sexual hormone levels in men with obstructive sleep apnea: efficacy of continuous positive airway pressure. Arch Sex Behav 2016;45:235-40.

26. Margel D, Cohen M, Livne PM, Pillar G. Severe, but not mild, obstructive sleep apnea syndrome is associated with erectile dysfunction. Urology 2004;63:545-9. 
27. Jeon YJ, Yoon DW, Han DH, Won TB, Kim DY, Shin HW. Low quality of life and depressive symptoms as an independent risk factor for erectile dysfunction in patients with obstructive sleep apnea. J Sex Med 2015;12:2168-77.

28. Shin HW, Rha YC, Han DH, Chung S, Yoon IY, Rhee CS, et al. Erectile dysfunction and disease-specific quality of life in patients with obstructive sleep apnea. Int J Impot Res 2008;20:549-53.

29. Fenz WD, Epstein S. Gradients of physiological arousal in parachutists as a function of an approaching jump. Psychosom Med 1967;29:33-51.

30. Schneider BK, Pickett CK, Zwillich CW, Weil JV, McDermott MT, Santen RJ, et al. Influence of testosterone on breathing during sleep. J Appl Physiol (1985) 1986;61:618-23.

31. Cistulli PA, Grunstein RR, Sullivan CE. Effect of testosterone administration on upper airway collapsibility during sleep. Am J Respir Crit Care Med 1994;149:530-2.

32. Fanfulla F, Malaguti S, Montagna T, Salvini S, Bruschi C, Crotti P, et al. Erectile dysfunction in men with obstructive sleep apnea: an early sign of nerve involvement. Sleep 2000;23:775-81.

33. Bouloukaki I, Papadimitriou V, Sofras F, Mermigkis C, Moniaki V, Siafakas NM, et al. Abnormal cytokine profile in patients with obstructive sleep apnea-hypopnea syndrome and erectile dysfunction. Mediators Inflamm 2014;2014:568951

34. Budweiser S, Luigart R, Jörres RA, Kollert F, Kleemann Y, Wieland WF, et al. Long-term changes of sexual function in men with obstructive sleep apnea after initiation of continuous positive airway pressure. J Sex Med 2013;10:524-31.

35. Acar M, Kaya C, Catli T, Hancı D, Bolluk O, Aydin Y. Effects of nasal continuous positive airway pressure therapy on partners' sexual lives. Eur Arch Otorhinolaryngol 2016;273:133-7.

36. Hoekema A, Stel AL, Stegenga B, van der Hoeven JH, Wijkstra PJ, van Driel MF, et al. Sexual function and obstructive sleep apnea-hypopnea: a randomized clinical trial evaluating the effects of oral-appliance and continuous positive airway pressure therapy. J Sex Med 2007;4:1153-62.

37. Knapp A, Myhill PC, Davis WA, Peters KE, Hillman D, Hamilton EJ, et al. Effect of continuous positive airway pressure therapy on sexual function and serum testosterone in males with type 2 diabetes and obstructive sleep apnoea. Clin Endocrinol (Oxf) 2014;81:254-8.

38. Santamaria JD, Prior JC, Fleetham JA. Reversible reproductive dysfunction in men with obstructive sleep apnoea. Clin Endocrinol (Oxf) 1988;28:461-70.

39. Shin HW, Park JH, Park JW, Rhee CS, Lee CH, Min YG, et al. Effects of surgical vs. nonsurgical therapy on erectile dysfunction and quality of life in obstructive sleep apnea syndrome: a pilot study. J Sex Med 2013;10:2053-9.

40. Pastore AL, Palleschi G, Ripoli A, Silvestri L, Maggioni C, Pagliuca G, et al. Severe obstructive sleep apnoea syndrome and erectile dysfunction: a prospective randomised study to compare sildenafil vs. nasal continuous positive airway pressure. Int J Clin Pract 2014;68:995-1000.

41. Melehan KL, Hoyos CM, Yee BJ, Wong KK, Buchanan PR, Grunstein RR, et al. Increased sexual desire with exogenous testosterone administration in men with obstructive sleep apnea: a randomized placebo-controlled study. Andrology 2016;4:55-61.

42. Kalejaiye O, Raheem AA, Moubasher A, Capece M, McNeillis S, Muneer A, et al. Sleep disorders in patients with erectile dysfunction. BJU Int 2017;120:855-60.

43. Morin CM, LeBlanc M, Daley M, Gregoire JP, Mérette C. Epidemiology of insomnia: prevalence, self-help treatments, consultations, and determinants of help-seeking behaviors. Sleep Med 2006;7:123-30.

44. Ohayon MM, Reynolds CF 3rd. Epidemiological and clinical relevance of insomnia diagnosis algorithms according to the DSM-IV and the International Classification of Sleep Disorders (ICSD). Sleep Med 2009;10:952-60.

45. Cho YW, Shin WC, Yun CH, Hong SB, Kim J, Earley CJ. Epidemiology of insomnia in Korean adults: prevalence and associated factors. J Clin Neurol 2009;5:20-3.

46. Shigehara K, Izumi K, Mizokami A, Namiki M. Testosterone deficiency and nocturia: a review. World J Mens Health 2017;35:14-21.

47. Luboshitzky R, Zabari Z, Shen-Orr Z, Herer P, Lavie P. Disruption of the nocturnal testosterone rhythm by sleep fragmentation in normal men. J Clin Endocrinol Metab 2001;86:1134-9.

48. Schmid SM, Hallschmid M, Jauch-Chara K, Lehnert H, Schultes B. Sleep timing may modulate the effect of sleep loss on testosterone. Clin Endocrinol (Oxf) 2012;77:749-54.

49. Knutson KL, Van Cauter E, Rathouz PJ, DeLeire T, Lauderdale DS. Trends in the prevalence of short sleepers in the USA: 1975-2006. Sleep 2010;33:37-45.

50. Liu Y, Wheaton AG, Chapman DP, Cunningham TJ, Lu $\mathrm{H}$, Croft JB. Prevalence of healthy sleep duration among adults: United States, 2014. MMWR Morb Mortal Wkly Rep 2016;65:137-41.

51. Park S, Cho MJ, Chang SM, Bae JN, Jeon HJ, Cho SJ, et al. Relationships of sleep duration with sociodemographic and health-related factors, psychiatric disorders and sleep disturbances in a community sample of Korean adults. J Sleep Res 2010;19:567-77.

52. Magee CA, Iverson DC, Caputi P. Sleep duration and obesity 
in middle-aged Australian adults. Obesity (Silver Spring) 2010;18:420-1.

53. Cappuccio FP, Taggart FM, Kandala NB, Currie A, Peile E, Stranges S, et al. Meta-analysis of short sleep duration and obesity in children and adults. Sleep 2008;31:619-26.

54. Jennings JR, Muldoon MF, Hall M, Buysse DJ, Manuck SB. Self-reported sleep quality is associated with the metabolic syndrome. Sleep 2007;30:219-23.

55. Yaggi HK, Araujo AB, McKinlay JB. Sleep duration as a risk factor for the development of type 2 diabetes. Diabetes Care 2006;29:657-61.

56. Buxton OM, Marcelli E. Short and long sleep are positively associated with obesity, diabetes, hypertension, and cardiovascular disease among adults in the United States. Soc Sci Med 2010;71:1027-36.

57. Buxton OM, Cain SW, O'Connor SP, Porter JH, Duffy JF, Wang W, et al. Adverse metabolic consequences in humans of prolonged sleep restriction combined with circadian disruption. Sci Transl Med 2012;4:129ra43.

58. Buxton OM, Pavlova M, Reid EW, Wang W, Simonson DC, Adler GK. Sleep restriction for 1 week reduces insulin sensitivity in healthy men. Diabetes 2010;59:2126-33.

59. Wu JL, Wu RS, Yang JG, Huang CC, Chen KB, Fang KH, et al. Effects of sleep deprivation on serum testosterone concentrations in the rat. Neurosci Lett 2011;494:124-9.

60. Carter JR, Durocher JJ, Larson RA, DellaValla JP, Yang H. Sympathetic neural responses to 24-hour sleep deprivation in humans: sex differences. Am J Physiol Heart Circ Physiol 2012;302:H1991-7.

61. Auyeung TW, Kwok T, Leung J, Lee JS, Ohlsson C, Vandenput L, et al. Sleep duration and disturbances were associated with testosterone level, muscle mass, and muscle strength: a cross-sectional study in 1274 older men. J Am Med Dir Assoc 2015;16:630.e1-6.

62. Leproult R, Van Cauter E. Effect of 1 week of sleep restriction on testosterone levels in young healthy men. JAMA 2011;305:2173-4.

63. Cote KA, McCormick CM, Geniole SN, Renn RP, MacAulay $\mathrm{SD}$. Sleep deprivation lowers reactive aggression and testosterone in men. Biol Psychol 2013;92:249-56.

64. Reynolds AC, Dorrian J, Liu PY, Van Dongen HP, Wittert GA, Harmer LJ, et al. Impact of five nights of sleep restriction on glucose metabolism, leptin and testosterone in young adult men. PLoS One 2012;7:e41218.

65. Auyeung TW, Lee JS, Kwok T, Leung J, Ohlsson C, Vandenput $\mathrm{L}$, et al. Testosterone but not estradiol level is positively related to muscle strength and physical performance independent of muscle mass: a cross-sectional study in 1489 older men. Eur J Endocrinol 2011;164:811-7.

66. Johnson JM, Nachtigall LB, Stern TA. The effect of testosterone levels on mood in men: a review. Psychosomatics 2013;54:509-14.

67. Gaffney CD, Pagano MJ, Kuker AP, Stember DS, Stahl PJ. Osteoporosis and low bone mineral density in men with testosterone deficiency syndrome. Sex Med Rev 2015;3:298315.

68. American Sleep Disorders Association (ASDA). The international classification of sleep disorders: diagnostic and coding manual. Rochester (MN): ASDA; 1997.

69. American Psychiatric Association. Diagnostic and statistical manual of mental disorders-fourth edition (DSM-IV). Washington D.C.: American Psychiatric Association; 2000.

70. Drake CL, Roehrs T, Richardson G, Walsh JK, Roth T. Shift work sleep disorder: prevalence and consequences beyond that of symptomatic day workers. Sleep 2004;27:1453-62.

71. Wickwire EM, Geiger-Brown J, Scharf SM, Drake CL. Shift work and shift work sleep disorder: clinical and organizational perspectives. Chest 2017;151:1156-72.

72. Roth T. Shift work disorder: overview and diagnosis. J Clin Psychiatry 2012;73:e09.

73. Wright KP Jr, Bogan RK, Wyatt JK. Shift work and the assessment and management of shift work disorder (SWD). Sleep Med Rev 2013;17:41-54.

74. McMenamin TM. A time to work: recent trends in shift work and flexible schedules. Monthly Labor Review 2007;130:315.

75. Monk TH. Shift work. In: Kryger MH, Roth T, Dement WC, editors. Principles and practice of sleep medicine. 3rd ed. Philadelphia (PA): W.B. Saunders Co.; 2000;600-5.

76. Boivin DB, Boudreau P. Impacts of shift work on sleep and circadian rhythms. Pathol Biol (Paris) 2014;62:292-301.

77. James SM, Honn KA, Gaddameedhi S, Van Dongen HPA. Shift work: disrupted circadian rhythms and sleepimplications for health and well-being. Curr Sleep Med Rep 2017;3:104-12.

78. Barton J. Choosing to work at night: a moderating influence on individual tolerance to shift work. J Appl Psychol 1994;79:449-54.

79. Novak RD, Auvil-Novak SE. Focus group evaluation of night nurse shiftwork difficulties and coping strategies. Chronobiol Int 1996;13:457-63.

80. Vener KJ, Szabo S, Moore JG. The effect of shift work on gastrointestinal (GI) function: a review. Chronobiologia 1989;16:421-39.

81. Fischer FM, Morata TC, Latorre Mdo R, Krieg EF, Fiorini AC, Colacioppo S, et al. Effects of environmental and orga- 
nizational factors on the health of shiftworkers of a printing company. J Occup Environ Med 2001;43:882-9.

82. Nojkov B, Rubenstein JH, Chey WD, Hoogerwerf WA. The impact of rotating shift work on the prevalence of irritable bowel syndrome in nurses. Am J Gastroenterol 2010;105:842-7.

83. Mitler MM, Carskadon MA, Czeisler CA, Dement WC, Dinges DF, Graeber RC. Catastrophes, sleep, and public policy: consensus report. Sleep 1988;11:100-9.

84. Gold DR, Rogacz S, Bock N, Tosteson TD, Baum TM, Speizer FE, et al. Rotating shift work, sleep, and accidents related to sleepiness in hospital nurses. Am J Public Health 1992;82:1011-4.

85. Lee ML, Howard ME, Horrey WJ, Liang Y, Anderson C, Shreeve MS, et al. High risk of near-crash driving events following night-shift work. Proc Natl Acad Sci U S A 2016;113:176-81.

86. Kawachi I, Colditz GA, Stampfer MJ, Willett WC, Manson JE, Speizer FE, et al. Prospective study of shift work and risk of coronary heart disease in women. Circulation 1995;92:3178-82.

87. Knutsson A. Shift work and coronary heart disease. Scand J Soc Med Suppl 1989;44:1-36.

88. Fujino Y, Iso H, Tamakoshi A, Inaba Y, Koizumi A, Kubo $\mathrm{T}$, et al. A prospective cohort study of shift work and risk of ischemic heart disease in Japanese male workers. Am J Epidemiol 2006;164:128-35.

89. Ha M, Park J. Shiftwork and metabolic risk factors of cardiovascular disease. J Occup Health 2005;47:89-95.

90. Lin YC, Hsiao TJ, Chen PC. Shift work aggravates metabolic syndrome development among early-middle-aged males with elevated ALT. World J Gastroenterol 2009;15:5654-61.

91. De Bacquer D, Van Risseghem M, Clays E, Kittel F, De Backer G, Braeckman L. Rotating shift work and the metabolic syndrome: a prospective study. Int J Epidemiol 2009;38:84854.

92. Hansen J, Lassen CF. Nested case-control study of night shift work and breast cancer risk among women in the Danish military. Occup Environ Med 2012;69:551-6.

93. Wang XS, Armstrong ME, Cairns BJ, Key TJ, Travis RC. Shift work and chronic disease: the epidemiological evidence. Occup Med (Lond) 2011;61:78-89.

94. Matheson A, O'Brien L, Reid JA. The impact of shiftwork on health: a literature review. J Clin Nurs 2014;23:3309-20.

95. Puttonen S, Härmä M, Hublin C. Shift work and cardiovascular disease - pathways from circadian stress to morbidity. Scand J Work Environ Health 2010;36:96-108.

96. Vogel M, Braungardt T, Meyer W, Schneider W. The effects of shift work on physical and mental health. J Neural Transm (Vienna) 2012;119:1121-32.

97. Baker FC, Driver HS. Circadian rhythms, sleep, and the menstrual cycle. Sleep Med 2007;8:613-22.

98. Labyak S, Lava S, Turek F, Zee P. Effects of shiftwork on sleep and menstrual function in nurses. Health Care Women Int 2002;23:703-14

99. Lauria L, Ballard TJ, Caldora M, Mazzanti C, Verdecchia A. Reproductive disorders and pregnancy outcomes among female flight attendants. Aviat Space Environ Med 2006;77:533-9.

100. Touitou Y, Motohashi Y, Reinberg A, Touitou C, Bourdeleau $\mathrm{P}$, Bogdan A, et al. Effect of shift work on the night-time secretory patterns of melatonin, prolactin, cortisol and testosterone. Eur J Appl Physiol Occup Physiol 1990;60:288-92.

101. Pastuszak AW, Moon YM, Scovell J, Badal J, Lamb DJ, Link $\mathrm{RE}$, et al. Poor sleep quality predicts hypogonadal symptoms and sexual dysfunction in male nonstandard shift workers. Urology 2017;102:121-5.

102. Lockley SW, Skene DJ, Arendt J, Tabandeh H, Bird AC, Defrance R. Relationship between melatonin rhythms and visual loss in the blind. J Clin Endocrinol Metab 1997;82:376370 .

103. Sack RL, Lewy AJ, Blood ML, Keith LD, Nakagawa H. Circadian rhythm abnormalities in totally blind people: incidence and clinical significance. J Clin Endocrinol Metab 1992;75:127-34.

104. Oren DA, Wehr TA. Hypernyctohemeral syndrome after chronotherapy for delayed sleep phase syndrome. N Engl J Med 1992;327:1762.

105. Caliyurt O, James FO, Boivin DB. Characterization of a non24-hour sleep-wake syndrome after traumatic brain injury. Sleep 2002;25:A189-90.

106. Randler C, Ebenhöh N, Fischer A, Höchel S, Schroff C, Stoll JC, et al. Chronotype but not sleep length is related to salivary testosterone in young adult men. Psychoneuroendocrinology 2012;37:1740-4.

107. Allen RP, Picchietti D, Hening WA, Trenkwalder C, Walters AS, Montplaisi J. Restless legs syndrome: diagnostic criteria, special considerations, and epidemiology. A report from the restless legs syndrome diagnosis and epidemiology workshop at the National Institutes of Health. Sleep Med 2003;4:10119.

108. Natarajan R. Review of periodic limb movement and restless leg syndrome. J Postgrad Med 2010;56:157-62.

109. Gao X, Schwarzschild MA, O’Reilly EJ, Wang H, Ascherio A. Restless legs syndrome and erectile dysfunction. Sleep 2010;33:75-9. 
110. Berger K, Luedemann J, Trenkwalder C, John U, Kessler C. Sex and the risk of restless legs syndrome in the general population. Arch Intern Med 2004;164:196-202.

111. Rothdach AJ, Trenkwalder C, Haberstock J, Keil U, Berger K. Prevalence and risk factors of RLS in an elderly population: the MEMO study. Memory and Morbidity in Augsburg Elderly. Neurology 2000;54:1064-8.

112. Li Y, Batool-Anwar S, Kim S, Rimm EB, Ascherio A, Gao X. Prospective study of restless legs syndrome and risk of erectile dysfunction. Am J Epidemiol 2013;177:1097-105.

113. Kurt O, Yazici CM, Alp R, Sancak EB, Topcu B. Is it only a sleeping disorder or more? Restless legs syndrome and erectile function. Scand J Urol 2016;50:392-5.

114. Dikici S, Bahadir A, Baltaci D, Ankarali H, Eroglu M, Ercan $\mathrm{N}$, et al. Association of anxiety, sleepiness, and sexual dysfunction with restless legs syndrome in hemodialysis patients. Hemodial Int 2014;18:809-18.

115. Ulfberg J, Nyström B, Carter N, Edling C. Prevalence of restless legs syndrome among men aged 18 to 64 years: an association with somatic disease and neuropsychiatric symptoms. Mov Disord 2001;16:1159-63.

116. Aurora RN, Kristo DA, Bista SR, Rowley JA, Zak RS, Casey $\mathrm{KR}$, et al. The treatment of restless legs syndrome and periodic limb movement disorder in adults: an update for 2012: practice parameters with an evidence-based systematic review and meta-analyses: an American Academy of Sleep Medicine Clinical Practice Guideline. Sleep 2012;35:1039-62.

117. Romigi A, Vitrani G, D’Aniello A, Di Gennaro G. Amelioration of untreated restless legs syndrome by tadalafil in a patient with erectile dysfunction. Clin Neuropharmacol 2015;38:62.

118. Wijemanne S, Ondo W. Restless legs syndrome: clinical features, diagnosis and a practical approach to management. Pract Neurol 2017;17:444-52.

119. Hirshkowitz M, Karacan I, Arcasoy MO, Acik G, Williams RL. The prevalence of periodic limb movements during sleep in men with erectile dysfunction. Biol Psychiatry 1989;26:541-4.

120. Ancoli-Israel S, Kripke DF, Mason W, Messin S. Sleep apnea and nocturnal myoclonus in a senior population. Sleep 1981;4:349-58.

121. Abad VC, Guilleminault C. New developments in the management of narcolepsy. Nat Sci Sleep 2017;9:39-57.

122. Thannickal TC, Moore RY, Nienhuis R, Ramanathan L, Gulyani S, Aldrich M, et al. Reduced number of hypocretin neurons in human narcolepsy. Neuron 2000;27:469-74.

123. Karacan I. Erectile dysfunction in narcoleptic patients. Sleep 1986;9:227-31.
124. van Kerrebroeck P, Abrams P, Chaikin D, Donovan J, Fonda D, Jackson S, et al. The standardisation of terminology in nocturia: report from the Standardisation Sub-committee of the International Continence Society. Neurourol Urodyn 2002;21:179-83.

125. Middelkoop HA, Smilde-van den Doel DA, Neven AK, Kamphuisen HA, Springer CP. Subjective sleep characteristics of 1,485 males and females aged 50-93: effects of sex and age, and factors related to self-evaluated quality of sleep. J Gerontol A Biol Sci Med Sci 1996;51:M108-15.

126. Burgio KL, Johnson TM 2nd, Goode PS, Markland AD, Richter HE, Roth DL, et al. Prevalence and correlates of nocturia in community-dwelling older adults. J Am Geriatr Soc 2010;58:861-6.

127. Bliwise DL, Foley DJ, Vitiello MV, Ansari FP, Ancoli-Israel S, Walsh JK. Nocturia and disturbed sleep in the elderly. Sleep Med 2009;10:540-8.

128. Kim MK, Zhao C, Kim SD, Kim DG, Park JK. Relationship of sex hormones and nocturia in lower urinary tract symptoms induced by benign prostatic hyperplasia. Aging Male 2012;15:90-5.

129. Liao CH, Chiang HS, Yu HJ. Serum testosterone levels significantly correlate with nocturia in men aged 40-79 years. Urology 2011;78:631-5.

130. Møller MK, Høyer S, Jensen JB. Extended versus superextended lymph-node dissection in radical cystectomy: subgroup analysis of possible recurrence-free survival benefit. Scand J Urol 2016;50:175-80.

131. Liu HY, Chung MS, Wang HJ, Liu RT, Chuang YC. Nocturia indicates a poor health status and increases mortality in male patients with type 2 diabetes mellitus. Int Urol Nephrol 2016;48:1209-14.

132. Kim JW, Oh MM, Yoon CY, Bae JH, Kim JJ, Moon du G. Nocturnal polyuria and decreased serum testosterone: is there an association in men with lower urinary tract symptoms? Int J Urol 2014;21:518-23.

133. Shigehara K, Konaka H, Koh E, Izumi K, Kitagawa Y, Mizokami A, et al. Effects of testosterone replacement therapy on nocturia and quality of life in men with hypogonadism: a subanalysis of a previous prospective randomized controlled study in Japan. Aging Male 2015;18:169-74.

134. Chang SC, Lin AT, Chen KK, Chang LS. Multifactorial nature of male nocturia. Urology 2006;67:541-4.

135. Pressman MR, Figueroa WG, Kendrick-Mohamed J, Greenspon LW, Peterson DD. Nocturia. A rarely recognized symptom of sleep apnea and other occult sleep disorders. Arch Intern Med 1996;156:545-50.

136. Umlauf MG, Chasens ER, Greevy RA, Arnold J, Burgio KL, 
Pillion DJ. Obstructive sleep apnea, nocturia and polyuria in older adults. Sleep 2004;27:139-44.

137. Martin SA, Appleton SL, Adams RJ, Taylor AW, Catcheside PG, Vakulin A, et al. Nocturia, other lower urinary tract symptoms and sleep dysfunction in a community-dwelling cohort of men. Urology 2016;97:219-26.

138. Yamamoto U, Nishizaka M, Yoshimura C, Kawagoe N, Hayashi A, Kadokami T, et al. Prevalence of sleep disordered breathing among patients with nocturia at a urology clinic. Intern Med 2016;55:901-5.

139. Maeda T, Fukunaga K, Nagata H, Haraguchi M, Kikuchi E, Miyajima A, et al. Obstructive sleep apnea syndrome should be considered as a cause of nocturia in younger patients without other voiding symptoms. Can Urol Assoc J 2016;10:E241-5.

140. Basoglu OK, Tasbakan MS. Gender differences in clinical and polysomnographic features of obstructive sleep apnea: a clinical study of 2827 patients. Sleep Breath 2018;22:241-9.

141. Bliwise DL. Sleep in normal aging and dementia. Sleep 1993;16:40-81.

142. Buysse DJ, Browman KE, Monk TH, Reynolds CF 3rd, Fasiczka AL, Kupfer DJ. Napping and 24-hour sleep/wake patterns in healthy elderly and young adults. J Am Geriatr Soc 1992;40:779-86.

143. Dijk DJ, Duffy JF, Czeisler CA. Contribution of circadian physiology and sleep homeostasis to age-related changes in human sleep. Chronobiol Int 2000;17:285-311.

144. Endeshaw Y. Correlates of self-reported nocturia among community-dwelling older adults. J Gerontol A Biol Sci Med Sci 2009;64:142-8.

145. Weiss JP. Nocturia: “do the math". J Urol 2006;175:S16-8.

146. Duffy JF, Scheuermaier K, Loughlin KR. Age-related sleep disruption and reduction in the circadian rhythm of urine output: contribution to nocturia? Curr Aging Sci 2016;9:3443.

147. Scheuermaier K, Meyers M, Surprise M, Loughlin KR, Duffy JF. Reciprocal relationship between age-related sleep disruption and urological symptoms. BJU Int 2011;107:871-3.

148. Denys MA, Bruneel E, Van Laecke S, Nørgaard JP, Everaert K. Pitfalls and opportunities in multidisciplinary research about nocturia in adults. Acta Clin Belg 2017;72:2-5.

149. Miyazato M, Tohyama K, Touyama M, Nakamura H, Oshiro $\mathrm{T}$, Ueda $\mathrm{S}$, et al. Effect of continuous positive airway pressure on nocturnal urine production in patients with obstructive sleep apnea syndrome. Neurourol Urodyn 2017;36:376-9.

150. Wang T, Huang W, Zong H, Zhang Y. The efficacy of continuous positive airway pressure therapy on nocturia in patients with obstructive sleep apnea: a systematic review and metaanalysis. Int Neurourol J 2015;19:178-84. 